\title{
The hustle and bustle of city life: monitoring the effects of urbanisation in the African lesser bushbaby
}

\author{
Juan Scheun ${ }^{1,2}$, Nigel C. Bennett ${ }^{2}$, Andre Ganswindt ${ }^{1,2,3}$, Julia Nowack ${ }^{4,5}$ \\ ${ }^{1}$ Endocrine Research Laboratory, Department of Anatomy and Physiology, University of Pretoria, Onderstepoort \\ 0110, South Africa. \\ ${ }^{2}$ Department of Zoology and Entomology, University of Pretoria, Pretoria 0028, South Africa. \\ ${ }^{3}$ National Zoological Gardens of South Africa, Pretoria, 0001, South Africa. \\ ${ }^{4}$ Department of Animal Ecology and Conservation, Biocentre Grindel, University of Hamburg, 20146 Hamburg, \\ Germany. \\ ${ }^{5}$ School of Environmental \& Rural Science, Zoology, University of New England, 2351 Armidale, NSW, Australia. \\ Corresponding author: J Scheun \\ Old Faculty building, Onderstepoort Veterinarian Institute, Soutpansberg road, \\ Onderstepoort, Pretoria, 0110, South Africa \\ Jscheun@zoology.up.ac.za
}

\section{Abstract}

Urbanisation has become a severe threat to pristine natural areas, causing habitat loss and affecting indigenous animals. Species occurring within an urban fragmented landscape must cope with changes in vegetation type as well as high degrees of anthropogenic disturbance, both of which are possible key mechanisms contributing to behavioural changes and perceived stressors. We attempted to elucidate the effects of urbanisation on the African lesser bushbaby, Galago moholi, by (1) recording activity budgets and body condition (body mass index, BMI) of individuals of urban and rural populations and (2) further determining adrenocortical activity in both populations as a measure of stress via faecal glucocorticoid metabolite (fGCM) levels, following successful validation of an appropriate enzyme immunoassay test system (ACTH challenge test). We found that both sexes of the urban population had significantly higher BMls than their rural counterparts, while urban females had significantly higher fGCM concentrations than rural females. While individuals in the urban population fed mainly on provisioned anthropogenic food sources and spent comparatively more time resting and engaging in aggressive interactions, rural individuals fed almost exclusively on tree exudates and spent more time moving between food sources. Although interactions with humans are likely to be lower in 
nocturnal than in diurnal species, our findings show that the impact of urbanisation on nocturnal species is still considerable, affecting a range of ecological and physiological aspects.

Keywords: faecal glucocorticoids, anthropogenic disturbance, provisioned food, increased weight

\section{Acknowledgements}

We would like to thank the residence of Onderstepoort, Pretoria, as well as Nylsvley Nature Reserve, for the permission to work on their property for the duration of this study. In addition, we would like to thank Ms L Prinzloo for assisting in sample collection at Nylsvley Nature Reserve. We would also like to thank Prof. Dr. K.H. Dausmann for logistical support. The research conducted was accomplished with the financial assistance of the Deutsche Forschungsgemeinschaft (DFG; DA 1031/3-1/2) and the DST-NRF Sarchl Chair of Mammal Behavioural Ecology and Physiology.

\section{Introduction}

Urbanisation is defined as the development of rural land for urban use (Champion 2001) and has become an important factor contributing to large-scale habitat fragmentation. This leads to changes in habitat structure and plant diversity, as well as the homogenization and local extinctions of endemic wildlife species (McKinney 2006; Sauvajot et al. 1998). As detrimental as the effects of anthropogenic activities might be for the majority of animals affected, recent studies have demonstrated that the type and degree of responses to anthropogenic disturbances are variable and species specific (French et al. 2008). Fragment- or edgespecies are able to exploit urban resources, such as anthropogenic food, shelter, and water sources, ultimately thriving within the urban landscape (McKinney 2006; Parris and Hazell 2005). These fragment-species, which often include birds, lizards and small rodents 
(Dickman and Doncaster 1989; Koenig et al. 2001; Parris and Hazell 2005), do not always initiate a flight reaction in response to human activity, but rather display a high degree of tolerance, habituation and even attraction towards anthropogenic activities (Bejder et al. 2009). However, on the edges of human settlements, human-animal conflicts can often be observed, altering the socio-ecological parameters and inducing a stress response, as has been shown for a range of species (Fokidis et al. 2009; French et al. 2008; Manfredo and Dayer 2004; Yeo and Neo 2010).

This is particularly relevant to primate species who often occur in close proximity to urban areas, where an increase in human-primate interaction and conflict has been noted in the last decade (Hill and Wallace 2012; McKinney 2011). With limited area available for movement and foraging, primates turn to anthropogenic food sources, such as provisioned feeding spots or crop raiding, to survive within a highly humanized environment (Hoffman and O'Riain 2012). Food availability has been shown to be a key factor contributing to group dynamics, most notably population size and structure, as well as aggressive interactions among conspecifics (Chapman et al. 2015; Oro et al. 2004). As food provisioning in the urban habitat provides a constant source of nutrition, this can have a considerable impact on population ecology (Altmann and Muruthi 1988; Hill 1999). Hill (1999) for example demonstrated a 15-fold increase in aggressive interactions between groups of Japanese macaques, Macaca fuscata, utilizing provisioned foods compared to unprovisioned populations. Similarly, vervet monkeys (Cercopithecus aethiops) feeding on anthropogenic foods displayed greater intra-group aggression than conspecifics feeding on natural food sources (Brennan et al. 1985). Changes in daily activity budget have also been found between provisioned and unprovisioned chacma, savannah and olive baboons (Papio ursinus, P. cynocephalus, P. anubis, Altmann and Muruthi 1988; Forthman-Quick 1986; van Doorn et al. 2010). Urban populations not only have to deal with the stress linked to changes in their activity budget and group ecology, but are also subjected to novel stressors unique to the urban environment such as heavy vehicle traffic and roads (Spellerberg 1998), exotic 
predator species (Kristan III et al. 2003), as well as noise-and light pollution (Tuomainen and Candolin 2011).

Monitoring stress responses non-invasively has allowed scientists to gain unique insights into the response to stressors, even for species that are difficult to assess in the wild (Heistermann et al. 2006; Touma and Palme 2005). However, assays for non-invasive hormone measurements need to be carefully validated in terms of applicability for the species-specific hormone matrix of interest to ensure a reliable quantification of respective glucocorticoid metabolites (Touma and Palme 2005). Monitoring faecal glucocorticoid metabolites (fGCM), as an index of stress, has been done on a range of wild diurnal primate species such as black howler monkeys (Alouatta pigra, Martínez-Mota et al. 2007), Yucatan spider monkeys (Ateles geoffroyi yucatanensis, Rangel-Negrín et al. 2009) and red-bellied lemurs (Eulemur rubriventer, Tecot 2013), where a high degree of human-primate interaction usually correlates with an increase in glucocorticoid levels (George and Crooks 2006; Tecot 2013). However, no study has so far reported the effect of anthropogenic disturbances for a nocturnal species, where the presumed reduced potential for human-primate interaction should be reflected in less distinct adrenocortical activity.

As a result of urban encroachment on native habitats in the northern regions of South Africa, the African lesser bushbaby, Galago moholi, can be found within the confines of larger cities, such as Johannesburg and Pretoria, South Africa (pers. obs. J. Scheun). As no data currently exist regarding the effects of anthropogenic activities on population dynamics, adrenocortical activity or activity budget for nocturnal strepsirrhine primates, we aimed to (a) determine stress-related physiological responses in $G$. moholi, by performing an adrenocorticotropic hormone stimulation test (ACTH challenge test) using faecal samples, (b) determine whether urban populations of G. moholi display higher fGCM levels as a measure of stress compared to their rural counterparts, and (c) investigate the effect of urbanisation on the activity budget and body condition of $G$. moholi. 


\section{Materials and Methods}

Study species

G. moholi is a nocturnal strepsirrhine primate occurring in Acacia woodland regions of southern Africa (Bearder 1987; Nekaris and Bearder 2007). The diet of the bushbaby comprises primarily of insects and Acacia gum (Bearder and Martin 1980; Nowack et al. 2013) with opportunistic fruit feeding occurring when primary food sources are sparse or unavailable (Scheun et al. 2014). Sexual dimorphism is absent within the species, though male individuals are generally heavier than their female counterparts (males: 160-255 g, females: $142-229 \mathrm{~g}$, Harcourt and Bearder 1989). Although known to be a solitary forager and described as a non-gregarious species, G. moholi is frequently observed interacting with conspecifics in their native habitat, displaying low levels of pair and group cohesion (Bearder and Martin 1979; Nekaris and Bearder 2007). Unlike females of the closely related gray mouse lemur (Microcebus murinus, Radespiel and Zimmermann 2001), there are no data on G. moholi females displaying any signs of dominant behaviour towards male conspecifics.

\section{ACTH challenge test}

The ACTH challenge test was carried out on six adult G. moholi (three males and three females) housed in one large room for 13 days, under a natural light cycle, at Ithumela Primate Sanctuary (Buffelsdrift, South Africa, 253'55.79”S, 28¹9’30.82”E). All six individuals were captured in Pretoria and the surrounding suburban areas in 2011/2012 and were held in outside aviaries $(2.5 \times 1.5 \times 2.5 \mathrm{~m})$ for more than 2 years prior to this study. During the study, animals were fed a combination of fresh fruits, yogurt and cat pellets, with water being available ad libitum. Individuals were given an initial four day acclimatisation period to familiarise themselves with the new study setup, which included being kept inside, as well as frequent human presence during faecal sampling. Following the acclimatization period cages were checked hourly during the active period of G. moholi (19:00 h- 05:00 h), 
for nine nights and all voided faecal matter was collected. In the morning hours of the fifth day, an adrenocorticotropic hormone (ACTH) challenge test was performed. After capture, each of the six individuals was injected intramuscularly with synthetic ACTH (1-2 IU/kg of Synacthen $\AA$, Novartis, South Africa Pty Ltd). Subsequently, the animals were released into their individual cages and faecal sampling continued until day nine of the study. The entire study was performed with approval of the University of Pretoria Animal Use and Care Committee (Reference EC056-12).

\section{Study sites}

The rural population of G. moholi was studied at Nylsvley Nature Reserve (NNR, Limpopo, South Africa, $\left.24^{\circ} 38.802^{\prime} S-28^{\circ} 40.095^{\prime} E\right)$. NNR is a semi-arid, mixed bushveld region, containing a natural vegetation structure and a high degree of endemic plant diversity (Coetzee et al. 1977). With a small number of unpaved roads and daytime tourists visiting the park, NNR has remained relatively untouched by anthropogenic disturbance. The urban population of G. moholi was studied at Onderstepoort, a suburb within Pretoria (OP; Gauteng, South Africa, $\left.25^{\circ} 38.507-28^{\circ} 10.585^{\prime} \mathrm{E}\right)$, situated approximately $180 \mathrm{~km}$ from NNR. OP is comprised of numerous plot segments and industrial buildings, interspersed by tar roads. The area has undergone extensive anthropogenic disturbance, leaving the natural vegetation structure highly fragmented. A high degree of artificial light and human activity is also found within the region.

\section{Ambient temperature at study sites}

Both study sites have a hot, wet season from October to March and a cold, dry season from April to September. Observations were conducted during winter (July), when G. moholi is not reproductively active (Pullen et al. 2000). The temperature and rainfall data for the study period have been obtained from the local weather station within NNR and from the South African Weather Service for OP. During the study period, the mean minimum temperature for 
NNR and $\mathrm{OP}$ was $4.0 \pm 3.8^{\circ} \mathrm{C}$ and $2.6 \pm 2.6^{\circ} \mathrm{C}$, respectively. The mean maximum temperature for NNR and $\mathrm{OP}$ was $19.4 \pm 3.0^{\circ} \mathrm{C}$ and $20.0 \pm 2.8^{\circ} \mathrm{C}$, respectively. No significant difference in either minimum ( $t$-test, $t=2.0, d f=44, p=0.19$ ) or maximum ( $t$-test, $t=1.68, d f=44, p=0.16$ ) temperatures existed between study sites. Additionally, no rainfall was recorded during the study period at either site.

\section{Trapping and faecal sample collection}

At both study sites, animals were captured during July using self made walk-in live and sherman traps $(7 \times 7 \times 30.5 \mathrm{~cm}, \mathrm{H}$. B. Sherman Traps, Tallahassee, FL, USA) baited with banana, peanut butter and honey. All traps had floors designed to prevent faeces from rolling off and falling to the ground, while encouraging the flow of urine, through a run-off pathway, decreasing the risk of cross-contamination and increasing the ease of faecal sample collection. The traps were set late in the afternoon and checked hourly between 17:00 $\mathrm{h}$ and 05:00 h. All individuals spent $\leq 1$ hour within a trap before removal. After removal, trapped individuals were aged, sexed, weighed and body length was measured from nose to the base of the tail with a flexible measuring tape following Nowack et al. (2010), and all fresh faeces within the traps were collected. Individuals were handled for less than five minutes, without the use of anaesthesia, before being released at the exact spot of capture. All captured individuals were classified as adult based on teeth abrasion, reproductive status and body parameters (adult: $>15 \mathrm{~cm}$ in length; teeth blunt; testes or nipples visible; males: androgen-dependent penile spines forming at puberty, Dixson 1989; male: >150 g; female: >130 g). Body markings, such as notches in ears or broken teeth were used for individual identification. Additionally, small amounts of fur from an individual's tail were removed or individuals were marked with different colours of household food dye (Moir's dye, Bokomo foods, Atlantis, South Africa). Fifteen faecal samples, all from different individuals, were collected per site during the study period (OP: 4 females, 11 males; NNR: 7 females, 8 males). 


\section{Ad libitum follows}

Each study site had its own observer, with observations performed in parallel at both sites (21 consecutive nights; 7-28 July 2013; between 17:00 h and 05:00 h). Free-ranging individuals were located by shining headlamps and detecting eyeshine. All follows were conducted with the use of red filtered lights. After spotting a bushbaby, individual observation took place using ad libitum sampling (Altmann 1974) and continued until the individual went out of sight for > five minutes. In addition to group composition (alone, pair, group), observations further included the following behavioural categories: moving, resting, foraging, feeding (including both natural and provisioned food sources), drinking, communicating, selfgrooming, pair interactions (grooming, playing, fighting) and time spent on the ground (Tab 1).

Table 1. Ethogram listing the behaviours observed during the study as well as the respective definitions for each behaviour.

\begin{tabular}{|c|c|}
\hline Behaviour & Definition \\
\hline Moving & $\begin{array}{l}\text { Walking or jumping as a form of locomotion through vegetation or across ground } \\
\text { cover }\end{array}$ \\
\hline Resting & Individual sits stationary in one location with no action being performed \\
\hline Foraging & An individual walking with its head down, sniffing and searching for nutrient sources \\
\hline Feeding & The consumption of a nutrient source (gum, insects, anthropogenic sources) \\
\hline Drinking & The licking of water by an individual \\
\hline Communicating & Sound emitted by an individual as soft squeaks or loud calls \\
\hline Self-grooming & An individual "tooth-combing" or licking itself \\
\hline \multicolumn{2}{|l|}{ Pair interactions } \\
\hline Pair-grooming & One individual "tooth-combing" or licking another's fur \\
\hline Pair-playing & $\begin{array}{l}\text { The positive interaction of two individuals that encompasses jumping, grabbing, } \\
\text { rolling and soft vocalisation }\end{array}$ \\
\hline Fighting & $\begin{array}{l}\text { The negative interaction between two individuals which includes chasing, grappling, } \\
\text { biting and vocalisation. Often results in one individual being driven from an area. }\end{array}$ \\
\hline
\end{tabular}


To assure inter-observer reliability (IOR), both observers involved in the study conducted cooperative follows at NNR prior to the onset of the study. A total of ten separate animal follows were recorded during 3.4 hours of simultaneous observations and defined behaviours were compared (Tab. 1) The percentage agreement method was used for calculating the IOR score, using the equation: $I O R=\frac{A}{A+\left[\frac{D}{2}\right]}$, where $\mathrm{A}$ is the number of agreements and $D$ the number of disagreements between observers during each follow (Ostrov and Hart 2014). We then averaged the ten IORs to achieve an average IOR between the two observers $(89.9 \pm$ SE $0.03 \%)$.

During the actual study, a total of 160 (NNR: 67, OP: 93) follows were performed, amounting to a total of $62.3 \mathrm{~h}$ (NNR: $28.8 \mathrm{~h}$; OP: $33.5 \mathrm{~h}$ ) of observation time. The average time an individual was followed was $21.82 \pm$ standard error (SE) 1.71 and $25.82 \pm$ SE 4.02 min at OP and NNR, respectively. Observations were approximately evenly distributed between both sites (no significant difference in observation per 3-hour time period between sites; Chi Square test, $\left.X_{(4, N=156)}^{2}=2.26, p=0.52\right)$, as well as between the first and second half of the night (until midnight: NNR $55 \%$, OP $52 \%$; after midnight: NNR $45 \%$, OP $48 \%$ ). Although free-ranging populations from both sites were accustomed to humans, due to previous biological studies (NNR; Mzilikazi et al. 2006; Nowack et al. 2010; Nowack et al. 2013; Pullen et al. 2000) or frequent human interaction (OP), observers were never closer than five metres to an individual being followed.

\section{Faecal sample collection and extraction}

Collected faecal material was placed in $1.5 \mathrm{ml}$ microcentrifuge tubes, immediately stored on ice, and frozen within $20 \mathrm{~min}$ at $-20^{\circ} \mathrm{C}$ until further processing. Following fieldwork, frozen samples were lyophilised, pulverised, and sieved through a mesh to remove remaining fibrous material (Fieß et al. 1999). Subsequently, 50-55 mg of the faecal powder was extracted by vortexing for $15 \mathrm{~min}$ with $1.5 \mathrm{ml} 80 \%$ ethanol. Following centrifugation for 10 
min at $1500 \mathrm{~g}$, the supernatants were transferred into new microcentrifuge tubes and stored at $-20^{\circ} \mathrm{C}$ until analysis.

\section{Steroid analysis}

The enzyme immunoassay (EIA) validation and subsequent laboratory analyses were conducted at the Endocrine Research Laboratory at the Faculty of Veterinary Science, University of Pretoria. Faecal extracts resulting from the ACTH challenge test were measured for immunoreactive fGCM's using EIAs detecting 11,17-dioxoandrostanes (11,17-

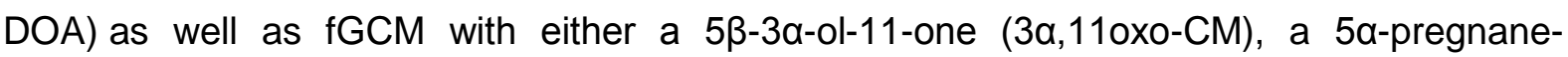

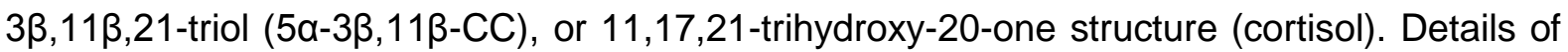
the four EIAs, including cross-reactivities, are described by Möstl et al. (2002) for 3a,11oxo-

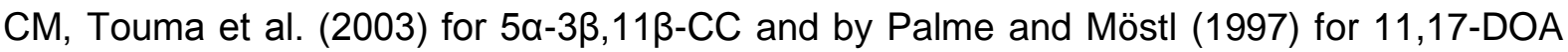
and cortisol. Sensitivities of the assays were $3 \mathrm{ng} / \mathrm{g}$ DW for 11,17-DOA and 3a,110xo-CM, and $1.5 \mathrm{ng} / \mathrm{g} \mathrm{DW}$ for $5 \alpha-3 \beta, 11 \beta-C C$ and cortisol. Serial dilutions of extracted faecal samples gave displacement curves that were parallel to the respective standard curves in all assays. Intra- and inter-assay coefficients of variation, determined by repeated measurements of high- and low- value quality controls ranged between $7.1 \%$ and $16.6 \%$ for 11,17 -DOA, 4.5 $\%$ and $16.9 \%$ for $3 \alpha, 110 x-C M, 6.7 \%$ and $16.6 \%$ for $5 \alpha-3 \beta, 11 \beta-C C$, and $9.5 \%$ and $18.5 \%$ for cortisol. Faecal samples from NNR and OP were analysed with the 11,17-DOA EIA only. Respective intra- and inter-assay coefficients of variation ranged between $7.1 \%$ and $9.9 \%$. Assays were performed on microtiter plates as described by Ganswindt et al. (2012).

\section{Data analysis}

Analytical statistics were performed using $R$ software (R 3.2.0, R Development Core Team 2013). We collected 150 faecal samples, from six individuals, during the ACTH challenge. During the field study period, we additionally collected 15 faecal samples, all from different 
individuals, per study site during the study period. Pre-ACTH administration median fGCM concentrations were calculated, for each individual during each EIA, with samples 48-6 hours prior to ACTH injection. Similarly, post-ACTH administration median fGCM concentrations for each individual, during each EIA, was calculated with samples 0-24 hours post ACTH injection. Subsequently, individual pre- and post-ACTH median values were pooled, for each EIA, and compared using a Wilcoxon signed-rank test. To quantify assayspecific responses following ACTH administration, individual fGCM baseline levels were determined using the fGCM values measured in collected samples 48 hours prior to ACTH injection. The body mass index for each captured individual was calculated using the equation $\mathrm{BMI}=M / L^{2}$, where $M$ is the weight $(\mathrm{kg})$ and $L$ the length $(\mathrm{m})$ of an individual. As our data were not normally distributed (Shapiro-Wilk test), differences in median values between groups were analysed using Mann-Whitney-U-test. Individual activity budgets were calculated to allow subsequent calculation of the average percentage time spent per activity within a population.

\section{Results}

\section{ACTH challenge test}

For each of the four EIAs tested, a significant increase in peak fGCM concentration, occurring 14-18 hours post-ACTH administration, was observed (Wilcoxon signed-rank test, $\mathrm{W}=0, \mathrm{df}=10, \mathrm{p}=0.031$, for all four assays). Three of the four EIAs used showed an overall increase in median fGCM concentrations of about $100 \%$ above fGCM baseline (11,17-DOA: $105 \%, 5 \alpha-3 \beta, 11 \beta-C C: 110 \%$, cortisol: $100 \%$; Fig. 1), but only the 11,17-DOA and $5 \alpha-$ $3 \beta, 11 \beta-C C$ EIAs revealed appropriate stable baseline values. Faecal GCM levels returned to pre-injection levels approximately twenty-four hours post-injection (Fig 1). Given the comparatively high variance in individual peak response values determined by the $5 \alpha-$ $3 \beta, 11 \beta-C C$ EIA, the $11,17-D O A$ EIA seems to be the most conservative assay for measuring 
fGCM values in G. moholi, and was used to analyse the samples collected at the urban and rural study sites.
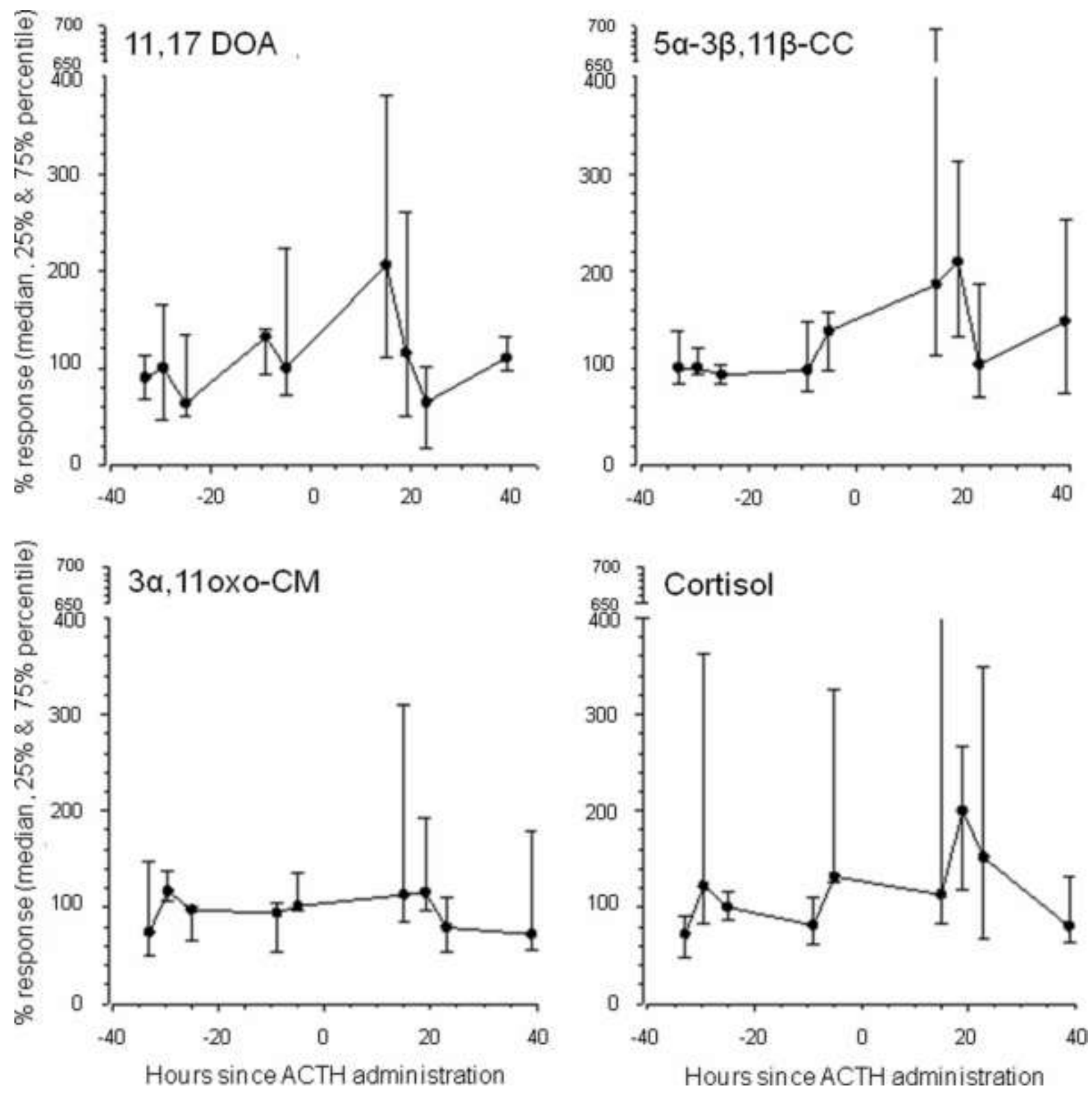

Figure 1. The response displayed by each of the four tested enzyme immunoassays following ACTH administration (time 0), with peak increases occurring 14-20 hours post-injection. Response is expressed as \% (median and $25 \%$ and $75 \%$ percentiles). Pre-injection baseline value was used as reference concentration and set as $100 \%$. 


\section{Comparison between study populations}

\section{Adrenocortical activity}

No statistically significant differences in fGCM levels were found when comparing respective values of male and females from the urban (male: $n=11$, female: $n=4$; U-test, $U=37$, $\mathrm{df}=13, \mathrm{p}=0.058$ ) or rural setting (male: $n=8$, female: $n=7$; U-test, $U=25, \mathrm{df}=13$, $p=0.73)$. Urban females had significantly higher fGCM levels compared to rural females $(U-$ test, $U=27$, df $=9, p=0.01$; urban: $66.2 \pm S E 19.1 \mathrm{ng} \cdot \mathrm{g}^{-1}$ dry weight; rural: $12.9 \pm$ SE 1.7 ng.g $^{-1}$ dry weight; Fig. 2). Similarly, a trend towards higher fGCM concentrations was found when comparing urban and rural males (U-test, $U=67, d f=17$, $\mathrm{p}=0.06$; urban: $24.7 \pm$ SE $5.1 \mathrm{ng} . \mathrm{g}^{-1}$ dry weight, rural: $13.3 \pm$ SE $1.2 \mathrm{ng} . \mathrm{g}^{-1}$ dry weight; Fig. 2).

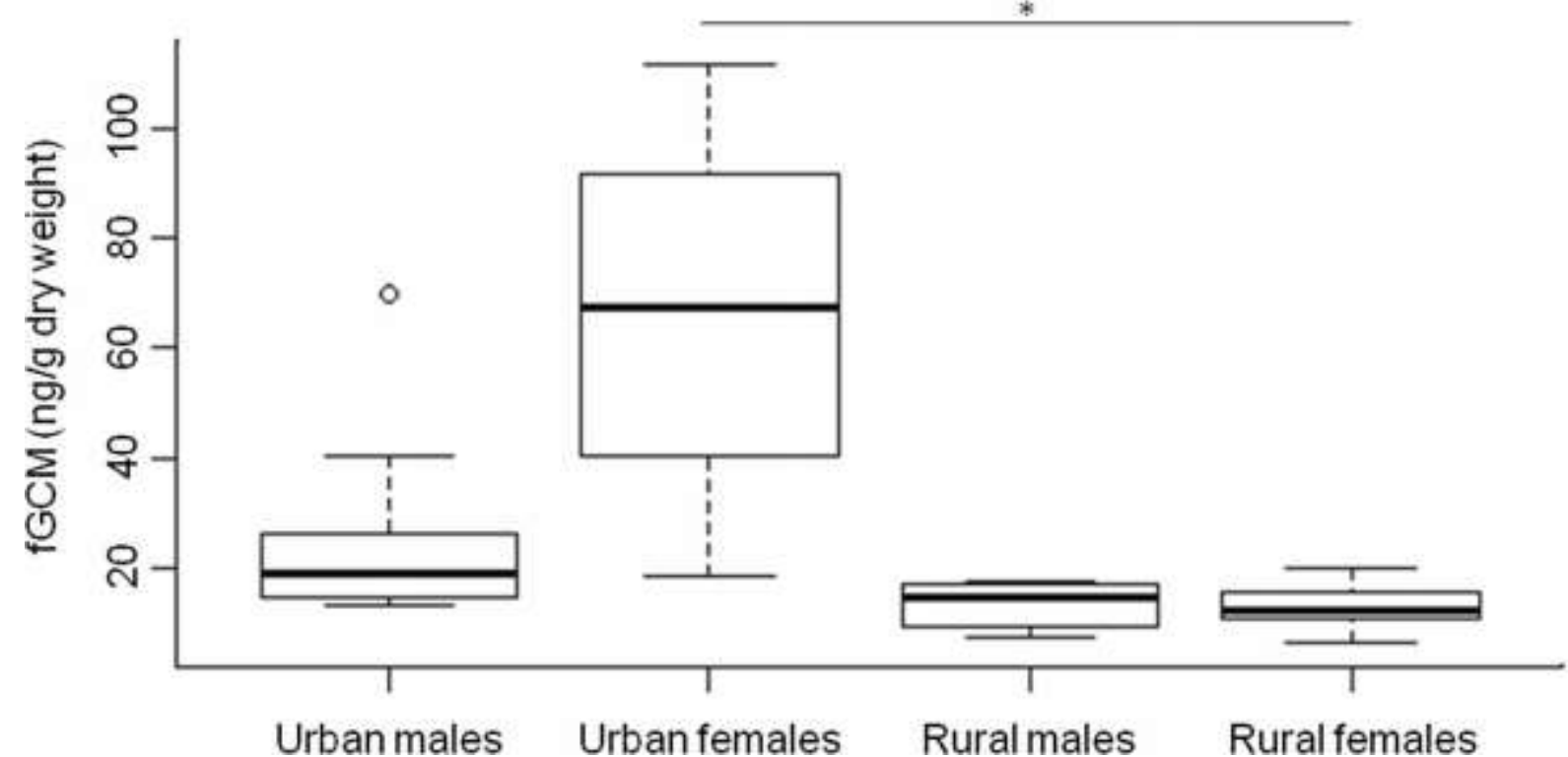

Figure 2. Concentrations of faecal glucocorticoid metabolites (fGCM) in G. moholi males and females inhabiting an urban $\left(n_{\text {males }}=11, n_{\text {females }}=4\right)$ or rural $\left(n_{\text {males }}=8, n_{\text {females }}=7\right)$ environment. Boxplots represent medians, 10th, 25th, 75th, and 90th percentiles and outliers (open circles). Significant differences are displayed by ${ }^{*}(p<0.05)$. 
Body mass index

We calculated BMI for all captured individuals of both populations (NNR: $n=15$, OP: $n=15$ )

(Tab. 2). Rural males showed significantly higher BMI values than rural females (male: $n=8$, female: $n=7$; U-test, $U=0$, df $=13, p=0.001$ ), while urban females displayed significantly higher BMI values than their male counterparts (male: $n=11$, female: $n=4$; U-test, $U=6$, $d f=13, p=0.03)$. We found a significant difference in BMI values between urban and rural females (U-test, $U=28$, df $=9, p=0.007$; urban: $7.4 \pm$ SE $0.3 \mathrm{~kg} \cdot \mathrm{m}^{-2}$; rural: $3.7 \pm \mathrm{SE} 0.13 \mathrm{~kg} \cdot \mathrm{m}^{-2} ;$ Fig. 3) as well as between urban and rural males (U-test, $U=76$, $d f=17, \quad p=0.008 ;$ urban: $6.5 \pm$ SE 0.22 kg.m $\mathrm{m}^{-2}$, rural: $5.2 \pm \mathrm{SE} 0.2 \mathrm{~kg} \cdot \mathrm{m}^{-2}$, Fig. 3).

Table 2. The body length, weight and calculated BMI values for each individual captured, within both rural and urban sites, during the study period.

\begin{tabular}{|c|c|c|c|}
\hline Rural & Weight (kg) & Body length (m) & BMI (kg.m $\left.{ }^{-2}\right)$ \\
\hline \multicolumn{4}{|l|}{ Female } \\
\hline 001 & 0.13 & 0.2 & 3.29 \\
\hline 002 & 0.17 & 0.2 & 4.25 \\
\hline 003 & 0.16 & 0.2 & 4 \\
\hline 004 & 0.13 & 0.19 & 3.29 \\
\hline 005 & 0.18 & 0.23 & 3.3 \\
\hline 006 & 0.13 & 0.19 & 3.41 \\
\hline 007 & 0.16 & 0.19 & 4 \\
\hline \multicolumn{4}{|l|}{ Male } \\
\hline 001 & 0.2 & 0.19 & 5.5 \\
\hline 002 & 0.19 & 0.19 & 5.1 \\
\hline 003 & 0.18 & 0.20 & 4.4 \\
\hline 004 & 0.2 & 0.19 & 5.5 \\
\hline 005 & 0.18 & 0.21 & 4.3 \\
\hline 006 & 0.2 & 0.19 & 5.5 \\
\hline 007 & 0.2 & 0.19 & 5.4 \\
\hline 008 & 0.19 & 0.19 & 5.3 \\
\hline Urban & Weight (kg) & Body length (m) & BMI (kg.m $\left.{ }^{-2}\right)$ \\
\hline \multicolumn{4}{|l|}{ Female } \\
\hline 001 & 0.19 & 0.16 & 7.42 \\
\hline 002 & 0.2 & 0.17 & 6.92 \\
\hline 003 & 0.18 & 0.16 & 7.03 \\
\hline 004 & 0.21 & 0.16 & 8.20 \\
\hline \multicolumn{4}{|l|}{ Male } \\
\hline 001 & 0.21 & 0.17 & 7.09 \\
\hline 002 & 0.2 & 0.18 & 6.17 \\
\hline 003 & 0.21 & 0.16 & 8.20 \\
\hline 004 & 0.21 & 0.18 & 6.48 \\
\hline 005 & 0.2 & 0.18 & 6.17 \\
\hline 006 & 0.19 & 0.17 & 6.75 \\
\hline 007 & 0.22 & 0.19 & 6.09 \\
\hline 008 & 0.2 & 0.18 & 6.17 \\
\hline 009 & 0.21 & 0.2 & 5.38 \\
\hline 010 & 0.2 & 0.18 & 6.17 \\
\hline 011 & 0.23 & 0.18 & 8.20 \\
\hline
\end{tabular}




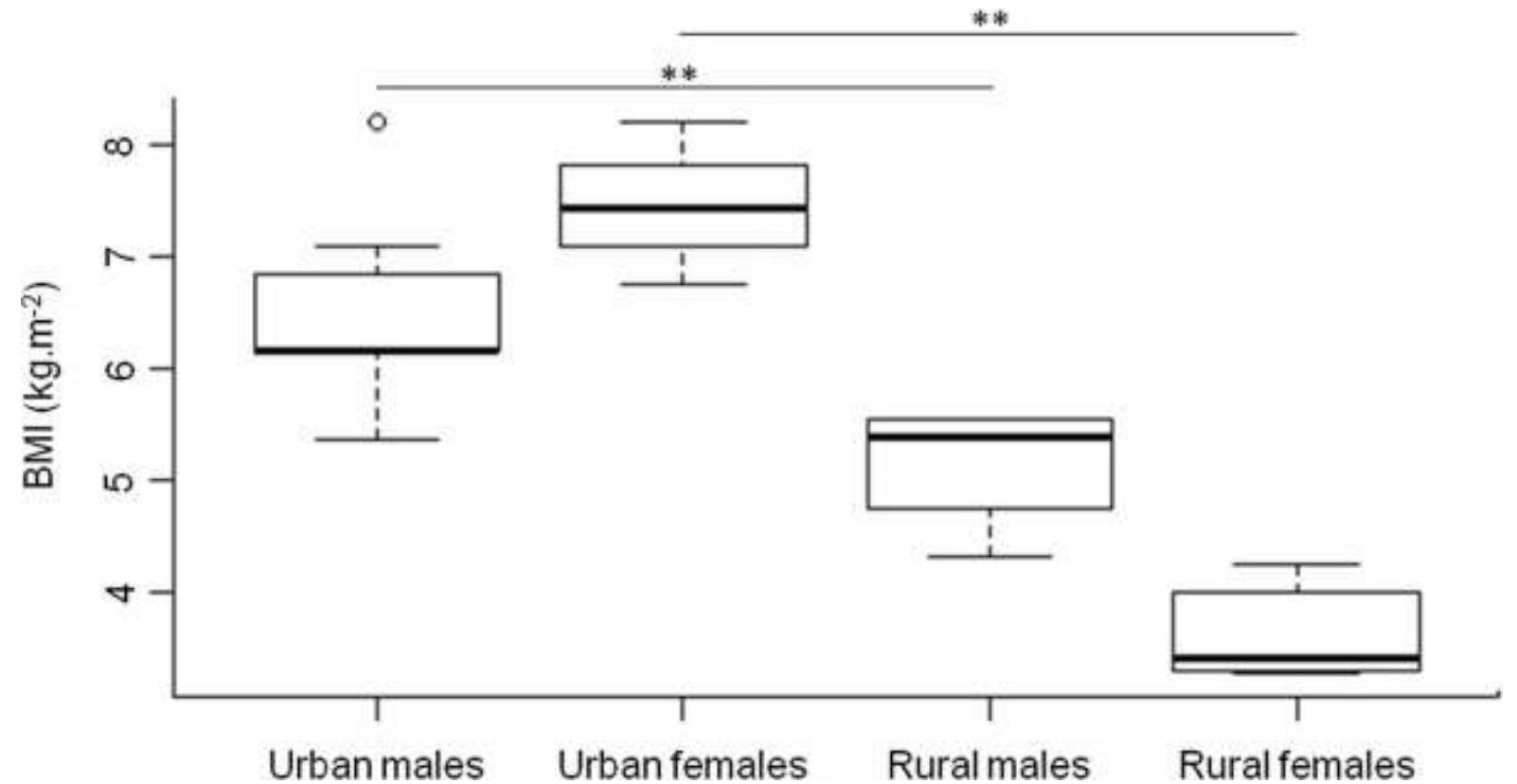

Figure 3. Body mass of $G$. moholi males and females inhabiting an urban ( $\left.n_{\text {males }}=11, n_{\text {females }}=4\right)$ or rural $\left(n_{\text {males }}=8, n_{\text {females }}=7\right)$ environment. Boxplots represent medians, 10th, 25th, 75th, and 90th percentiles and outliers (open circles). Significant differences are displayed by ${ }^{* *}(p<0.01)$.

Behavioural observations

During the study, G. moholi moved more frequently in pairs or groups within the urban habitat compared to the rural environment where they were seen mostly on their own (57.6 $\%$ vs. $12 \%$ ). Although individuals of both populations spent most of their time resting and moving, urban galagos spent considerably less time moving than the rural population (Fig. 4). Consequentially, urban individuals spent a higher percentage of their time on the remaining activities, compared to rural individuals, which included an increase in time spent feeding and calling (Fig. 4). The rural population fed almost exclusively on gum from Acacia trees $(96 \%)$ during the study period, while the urban population exploited anthropogenic food sources, such as bird feeders, to a much greater extent (84 \%), which included bread crumbs, fruits such as banana and apples and yogurt (Tab. 3). Provisioned feeding spots attracted a large number of individuals and we observed substantial group sizes of galagos per night (> 10 individuals). Around these feeding spots we observed a high number of 
interactions between galagos and domestics pets during the study ( $N>40$ ), while interactions with humans were comparatively lower $(N=9)$. Additionally, aggressive interactions between individuals were only present in the urban population of our study (Fig. 4).

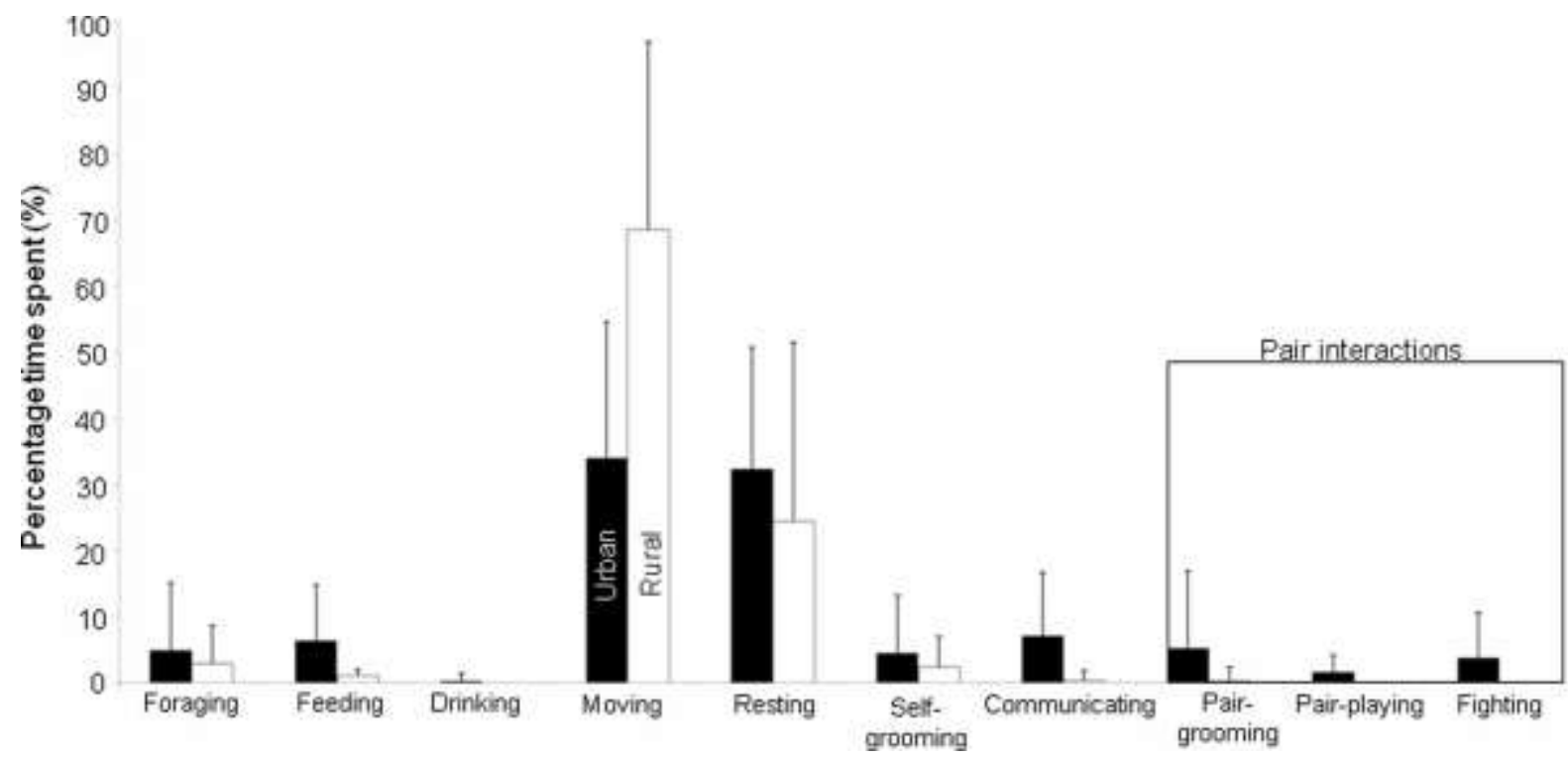

Figure 4. Frequency of time spent (mean \pm standard deviation) on various activities by urban (black bars) and rural (white bars) G. moholi populations during the study period.

Table 3. The \% of time spent feeding on each food source category during the course of the study by the rural and urban $G$. moholi population

\begin{tabular}{lll} 
Feeding sources & Urban & Rural \\
\hline Anthropogenic & 84.2 & - \\
Gum & 12.4 & 96.3 \\
Insects & 3.4 & 3.7
\end{tabular}

\section{Discussion}

This comparative study is the first to elucidate the effects of urbanisation on a nocturnal primate species, by monitoring changes in the daily activity as well as adrenocortical activity through measuring fGCM levels. It is clear from the findings of this study that urban individuals are not only affected in their behaviour and activity pattern, but also experience 
distinctively higher fGCM levels than rural individuals, although the effect was not statistically significant for male galagos.

The higher physiological stress seen in the urban animals compared to the rural population is consistent with what has been described for a variety of other species surviving within an urban landscape. For example, in a variety of birds, the most commonly studied clade of urbanized animals, species like the European blackbird, Turdus merula, and northern mockingbird, Mimus polyglottos, occurring in cities, show considerably higher glucocorticoid levels compared to their rural counterparts (Fokidis et al. 2009). Certain urban-specific circumstances might be responsible for the elevation in fGCM levels seen in urbanized individuals. Direct contact with humans, often perceived as a predator orientated threat, as well as encounters with unknown exotic predators such as pets, could well be perceived as stressors resulting in an alteration of respective endocrine correlates in individuals exploring an urban environment (Beale and Monaghan 2004; Maréchal et al. 2011; Shutt et al. 2014). Although human-animal interactions were seldom observed in this study, and are in general less likely than for a diurnal species, interactions with domestic cats and dogs were common and most likely present a severe threat to galagos.

Additionally, we frequently observed a high degree of G. moholi aggregation around provisioned feeding spots in urban areas. These individuals displayed changes in both their behaviour and activity not observed within the rural population monitored. Within the urban population we observed aggressive behaviour of females $(n=59)$ toward conspecifics approaching feeding spots, which included chasing, biting and high levels of vocalisation (pers. obs. Juan Scheun). Female dominance within non-human primates is often characterised by intense levels of intersexual aggression and feeding priority of females, especially in species where little or no sexual dimorphism is present (Kappeler 1990; Overdorff et al. 2005), and may well explain the high level of female aggression in urban $G$. moholi. Maternal investment, which leads to energetic strain, is likely an important mechanism driving the need of females to increase food consumption, increasing the level of 
intersexual resource competition (Sauther 1993). When these resources are clumped together, as in urban areas, resource competition intensifies, leading to an increase in aggressive and dominant female behaviour even in species that usually do not show female dominance, such as G. moholi (Hill 1999; Ram et al. 2003). Although female dominance secures feeding priority, both dominance status of male and females, as well as increased levels of aggression, have been shown to increase the adrenocortical activity of an individual, leading to an increase in glucocorticoid secretion (Creel 2001). The significantly higher fGCM levels of urban G. moholi females may well be a result of female dominance and intense levels of female aggression towards conspecifics.

In addition to the observed pattern of aggression, we found urban G. moholi display higher than expected levels of cohesion between conspecifics than previously described for the species (Bearder 1987). Although a low level of pair cohesion might be present in rural, free-ranging G. moholi populations (Bearder and Martin 1979), the high degree of pair- and especially group movement in our urban setup is surprising. Studies on "solitary", nocturnal primates have shown that low-level cohesion between males and females, with overlapping home ranges, occur, likely in an attempt to decrease predation, secure a viable mate, or defend other valuable resources (Müller 1998; Rasoloharijaona et al. 2000; Schülke and Kappeler 2003). As fragmentation of the landscape decreases the ability to disperse, while offering limited feeding opportunity and available mating partners, the level of cohesion observed in our urban population might well be an artefact of the urban habitat.

Our results clearly show that urban G. moholi utilise provisioned foods to a great extent, whereas rural populations, which did not have access to anthropogenic food sources, fed almost exclusively on gum sources during this time of the year. The constant nature of provisioned feeding locations potentially results in urban individuals spending less time moving and foraging and more time on pair interactions, such as pair-grooming and fighting, compared to their rural counterparts. Similar to our urban G. moholi population, substantial changes in the daily activity budget have been observed in a number of other primate 
species utilizing urban resources. For example, Forthman-Quick (1986) and Saj et al. (1999) found that populations of vervet monkeys (C. aethiops pygerthrus) and baboons ( $P$. anubis) who extensively utilise provisioned food sources, spent less time moving and foraging, but increase their social interaction activities.

The monitored urban G. moholi population had significantly higher BMI values compared to their rural counterparts, which might be a consequence of their extensive utilization of anthropogenic food sources and the associated reduction in foraging behaviour. The nature of these accessible foods, usually high in easily digestible fat and sugar content (Voragen 1998), as well as the over-utilization thereof by wildlife species, can lead to increases in body mass in provisioned compared to non-provisioned populations (Auman et al. 2008; Boutin 1990; Orams 2002). In humans, excessive body mass has been shown to lead to the chronic activation of the HPA-axis and glucocorticoid secretion (Björntorp and Rosmond 2000). Furthermore, the differences in diet of both populations could potentially have affected the fGCM concentration levels measured in this study. Differences in diet patterns have been shown to affect the composition and abundance of various gut bacteria in wildlife species (Pusateri et al. 1990) and could have therefore an effect on the degree of hormone metabolism performed and subsequently an influence on the hormone metabolite concentration excreted (Gorbach and Goldin 1987; Morrow et al. 2002). Although there are contradicting findings on the effect of diet on hormone metabolism and excretion (Dantzer et al. 2011; Goymann 2012), the use of anthropogenic food sources could be an important factor when quantifying fGCM excretion. Furthermore, food digestion and metabolism might vary between the sexes, ultimately reflected in sex-related differences in hormone metabolite excretion (Goymann 2012). However, since we did not find a difference in fGCM levels between the sexes of the rural population, it is unlikely that potentially existing sexdependent variation in food digestion and metabolism resulted in different fGCM values found for males and females of the urban population. 
Overall, the availability of provisioned food sources seems an important mechanism allowing urban G. moholi populations to survive within the urban habitat, especially during winter periods when natural food sources are scarce and individuals of the wild population show a shift from insect feeding to even less nutritional gum feeding (Nowack et al. 2013). However, a variety of urbanisation-related effects have been found, including overweight individuals and aggressive behaviour around provisioned feeding sites, correlating with increased fGCM concentrations. Although wildlife species who are active at night often have reduced rates of human-wildlife interaction (George and Crooks 2006), our study indicates that even nocturnal species, such as G. moholi, inhabiting urban landscape, can still be influenced by human disturbances.

\section{Compliance with Ethical Standards}

\section{Conflict of Interest}

The authors declare that they have no conflict of interest.

\section{Statement of human rights and Informed consent}

This article does not contain any studies with human participants performed by any of the authors.

\section{Statement on the welfare of animals}

All applicable international, national, and/or institutional guidelines for the care and use of animals were followed.

\section{References}

Altmann J (1974) Observational study of behavior: sampling methods. Behavior 49:227 - 267 Altmann J, Muruthi P (1988) Differences in daily life between semiprovisioned and wildfeeding baboons. Am J Primatol 15:213-221 doi:10.1002/ajp.1350150304

Auman HJ, Meathrel CE, Richardson A (2008) Supersize me: does anthropogenic food change the body condition of silver gulls? A comparison between urbanized and remote, non-urbanized areas. Waterbirds 31:122-126 doi:10.1675/15244695(2008)31[122:SMDAFC]2.0.CO;2

Beale CM, Monaghan P (2004) Human disturbance: people as predation-free predators? J Appl Ecol 41:335-343 doi:10.1111/j.0021-8901.2004.00900.x

Bearder SK (1987) Lorises, bushbabies, and tarsiers: diverse societies in solitary foragers. In: Smuts BB, Cheney DL, Seyfarth RM, Wrangham RW, Struhsaker TT (eds) Primate societies. University of Chicago Press, Chicago, pp 11-24 
Bearder SK, Martin RD (1979) The social organization of a nocturnal primate revealed by radio tracking. In: Amlaner Jr CJ, MacDonald W (eds) A Handbook on biotelemetry and radio tracking. Pergamon, Oxford, pp 633-648

Bearder SK, Martin RD (1980) Acacia gum and its use by bushbabies, Galago senegalensis (Primates: Lorisidae). Int J Primatol 1:103-128

Bejder L, Samuels A, Whitehead H, Finn H, Allen S (2009) Impact assessment research: use and misuse of habituation, sensitisation and tolerance in describing wildlife responses to anthropogenic stimuli. Mar Ecol Prog Ser 395:177-185 doi:10.3354/meps07979

Björntorp P, Rosmond R (2000) Obesity and cortisol. Nutr 16:924-936 doi:http://dx.doi.org/10.1016/S0899-9007(00)00422-6

Boutin S (1990) Food supplementation experiments with terrestrial vertebrates: patterns, problems, and the future. Can J Zool 68:203-220 doi:10.1139/z90-031

Brennan EJ, Else JG, Altmann J (1985) Ecology and behaviour of a pest primate: vervet monkeys in a tourist-lodge habitat. Afr $J$ Ecol 23:35-44 doi:10.1111/j.13652028.1985.tb00710.x

Champion T (2001) Urbanization, suburbanization, counterurbanization and reurbanization. In: Paddison R (ed) Handbook of urban studies. SAGE Publication Ltd, London, pp 143-145

Chapman CA, Schoof VA, Bonnell TR, Gogarten JF, Calmé S (2015) Competing pressures on populations: long-term dynamics of food availability, food quality, disease, stress and animal abundance. Phil Trans R Soc B 370:20140112

Coetzee BJ, van der Meulen F, Zwanziger S, Gonsalves P, Weisser PJ (1977) A phytosociological classification of the Nylsvley Nature Reserve. S Afr Natl Sci Progr Rep 20:1-22

Creel S (2001) Social dominance and stress hormones. Trends Ecol Evol 16:491-497

Dantzer B, McAdam AG, Palme R, Boutin S, Boonstra R (2011) How does diet affect fecal steroid hormone metabolite concentrations? An experimental examination in red squirrels. Gen Comp Endocrinol 174:124-131 doi:10.1016/j.ygcen.2011.08.010

Dickman CR, Doncaster CP (1989) The ecology of small mammals in urban habitats II. Demography and dispersal. J Anim Ecol 58:119-127 doi:10.2307/4989

Dixson AF (1989) Sexual selection, genital morphology, and copulatory behaviour in male galagos. Int J Primatol 10: 47-55

Fieß M, Heistermann M, Hodges JK (1999) Patterns of urinary and fecal steroid excretion during the ovarian cycle and pregnancy in the African elephant (Loxodonta africana). Gen Comp Endocrinol 115:76-89 doi:http://dx.doi.org/10.1006/gcen.1999.7287

Fokidis HB, Orchinik M, Deviche P (2009) Corticosterone and corticosteroid binding globulin in birds: relation to urbanization in a desert city. Gen Comp Endocrinol 160:259-270 doi:http://dx.doi.org/10.1016/j.ygcen.2008.12.005

Forthman-Quick DL (1986) Activity budget and the consumption of human food of two troops of baboons, Papio anubis, at Gilgil, Kenya. In: Else JG, Lee PC (eds) Primate ecology and conservation. Cambridge University Press, Cambridge, pp 221-227

French S, Fokidis HB, Moore M (2008) Variation in stress and innate immunity in the tree lizard (Urosaurus ornatus) across an urban-rural gradient. J Comp Physiol B 178:997-1005 doi:10.1007/s00360-008-0290-8

Ganswindt A, Tordiffe ASW, Stam E, Howitt MJ, Jori F (2012) Determining adrenocortical activity as a measure of stress in African bufallo (Syncerus caffer) based on faecal analysis. Afr Zool 47:261-269

George SL, Crooks KR (2006) Recreation and large mammal activity in an urban nature reserve. Biol Conserv 133:107-117 doi:http://dx.doi.org/10.1016/j.biocon.2006.05.024

Gorbach SL, Goldin BR (1987) Diet and the excretion and enterohepatic cycling of estrogens. Preventive Med 16:525-531

Goymann W (2012) On the use of non-invasive hormone research in uncontrolled, natural environments: the problem with sex, diet, metabolic rate and the individual. Methods in Ecol and Evol 3:757-765 doi:10.1111/j.2041-210X.2012.00203.x 
Harcourt C, Bearder S (1989) A comparison of Galago moholi in South Africa with Galago zanzibaricus in Kenya. Int J Primatol 10:35-45 doi:10.1007/BF02735702

Heistermann M, Palme R, Ganswindt A (2006) Comparison of different enzymeimmunoassays for assessment of adrenocortical activity in primates based on fecal analysis. Am J Primatol 68:257-273 doi:10.1002/ajp.20222

Hill C, Wallace G (2012) Crop protection and conflict mitigation: reducing the costs of living alongside non-human primates. Biodivers Conserv 21:2569-2587 doi:10.1007/s10531-012-0318-y

Hill D (1999) Effects of provisioning on the social behaviour of Japanese and rhesus macaques: implications for socioecology. Primates 40:187-198 doi:10.1007/BF02557710

Hoffman TS, O'Riain MJ (2012) Landscape requirements of a primate population in a human-dominated environment. Front Zool 9:1-17

Kappeler PM (1990) The evolution of sexual size dimorphism in prosimian primates. Am J Primatol 21:201-214 doi:10.1002/ajp.1350210304

Koenig J, Shine R, Shea G (2001) The ecology of an Australian reptile icon: how do bluetongued lizards (Tiliqua scincoides) survive in suburbia? Wildl Res 28:214-227 doi:http://dx.doi.org/10.1071/WR00068

Kristan III WB, Lynam AJ, Price MV, Rotenberry JT (2003) Alternative causes of edgeabundance relationships in birds and small mammals of California coastal sage scrub. Ecogr 26:29-44 doi:10.1034/j.1600-0587.2003.03341.x

Manfredo MJ, Dayer AA (2004) Concepts for Exploring the Social Aspects of HumanWildlife Conflict in a Global Context. Human Dimensions of Wildlife 9:1-20 doi:10.1080/10871200490505765

Maréchal L, Semple S, Majolo B, Qarro M, Heistermann M, MacLarnon A (2011) Impacts of tourism on anxiety and physiological stress levels in wild male Barbary macaques. Biol Conserv 144:2188-2193 doi:http://dx.doi.org/10.1016/j.biocon.2011.05.010

Martínez-Mota R, Valdespino C, Sánchez-Ramos MA, Serio-Silva JC (2007) Effects of forest fragmentation on the physiological stress response of black howler monkeys. Anim Conserv 10:374-379 doi:10.1111/j.1469-1795.2007.00122.x

McKinney ML (2006) Urbanization as a major cause of biotic homogenization. Biol Conserv 127:247-260 doi:http://dx.doi.org/10.1016/j.biocon.2005.09.005

McKinney $T$ (2011) The effects of provisioning and crop-raiding on the diet and foraging activities of human-commensal white-faced Capuchins (Cebus capucinus). Am J Primatol 73:439-448 doi:10.1002/ajp.20919

Morrow CJ, Kolver ES, Verkerk GA, Matthews LR (2002) Fecal glucocorticoid metabolites as a measure of adrenal activity in dairy cattle. Gen Comp Endocrinol 126:229-241

Möstl E, Maggs JL, Schrötter G, Besenfelder U, Palme R (2002) Measurement of cortisol metabolites in faeces of ruminants. Vet Res Commun 26:127-139 doi:10.1023/A:1014095618125

Müller AE (1998) A preliminary report on the social organisation of Cheirogaleus medius (Cheirogaleidae; Primates) in north-west Madagascar. Folia Primatol 69:160-166

Mzilikazi N, Masters JC, Lovegrove BG (2006) Lack of torpor in free-ranging southern lesser galagos, Galago moholi: ecological and physiological considerations. Folia Primatol 77:465-476 doi:10.1159/000095392

Nekaris A, Bearder SK (2007) The lorisiform primates of Asia and mainland Africa: diversity shrouded in darkness. In: Campbell CJ, Fuentes A, Mackinnon KC, Panger M, Bearder SK (eds) Primates in perspective. Oxford University Press, New York, pp 2445

Nowack J, Mzilikazi N, Dausmann KH (2010) Torpor on demand: heterothermy in the nonlemur primate Galago moholi. PLoS ONE 5:e10797 doi:10.1371/journal.pone.0010797

Nowack J, Wippich M, Mzilikazi N, Dausmann KH (2013) Surviving the cold, dry period in Africa: behavioral adjustments as an alternative to heterothermy in the African lesser bushbaby (Galago moholi). Int J Primatol 34:49-64 
Orams MB (2002) Feeding wildlife as a tourism attraction: a review of issues and impacts. Tour Manag 23:281-293 doi:http://dx.doi.org/10.1016/S0261-5177(01)00080-2

Oro D, Cam E, Pradel R, Martínez-Abraín A (2004) Influence of food availability on demography and local population dynamics in a long-lived seabird. Proc $\mathrm{R}$ Soc Lond B: Biol Sci 271:387-396

Ostrov JM, Hart E (2014) Observational methods. In: Little TD (ed) The Oxford handbook of quantitative methods in psychology: foundations, vol 1. Oxford University Press, Oxford, UK, p 286

Overdorff DJ, Erhart EM, Mutschler T (2005) Does female dominance facilitate feeding priority in black-and-white ruffed lemurs (Varecia variegata) in southeastern Madagascar? Am J Primatol 66:7-22 doi:10.1002/ajp.20125

Palme R, Möstl E (1997) Measurement of cortisol metabolites in faeces of sheep as a parameter of cortisol concentration in blood. Int J Mamm Biol 62:192-197

Parris KM, Hazell DL (2005) Biotic effects of climate change in urban environments: the case of the grey-headed flying-fox (Pteropus poliocephalus) in Melbourne, Australia. Biol Conserv 124:267-276 doi:http://dx.doi.org/10.1016/j.biocon.2005.01.035

Pullen SL, Bearder SK, Dixson AF (2000) Preliminary observations on sexual behavior and the mating system in free-ranging lesser galagos (Galago moholi). Am J Primatol $51: 79-88$

Pusateri DJ, Roth WT, Ross JK, Shultz TD (1990) Dietary and hormonal evaluation of men at different risks for prostate cancer: plasma and fecal hormone-nutrient interrelationships. Am J Clin Nutr 51:371-377

R Development Core Team (2013) R: A language and environment for statistical computing. R Foundation for Statistical computing. Vienna, Austria. ISBN 3-900051-07-0, URL http://www.R-project.org/

Radespiel U, Zimmermann E (2001) Female dominance in captive gray mouse lemurs (Microcebus murinus). Am J Primatol 54:181-192

Ram S, Venkatachalam S, Sinha A (2003) Changing social strategies of wild female bonnet macaques during natural foraging and on provisioning. Curr Sci Bangalore 84:780790

Rangel-Negrín A, Alfaro JL, Valdez RA, Romano MC, Serio-Silva JC (2009) Stress in Yucatan spider monkeys: effects of environmental conditions on fecal cortisol levels in wild and captive populations. Anim Conserv 12:496-502 doi:10.1111/j.14691795.2009.00280.x

Rasoloharijaona S, Rakotosamimanana B, Zimmermann E (2000) Infanticide by a male Milne-Edwards' sportive lemur (Lepilemur edwardsi) in Ampijoroa, nw-Madagascar. Int J Primatol 21:41-45 doi:10.1023/A:1005419528718

Saj T, Sicotte P, Paterson JD (1999) Influence of human food consumption on the time budget of vervets. Int J Primatol 20:977-994 doi:10.1023/A:1020886820759

Sauther ML (1993) Resource competition in wild populations of ringtailed lemurs (Lemur catta): implications for female dominance. In: Kappeler P, Ganzhorn J (eds) Lemur social systems and their ecological basis. Springer US, pp 135-152. doi:10.1007/9781-4899-2412-4_10

Sauvajot R, Buechner M, Kamradt D, Schonewald C (1998) Patterns of human disturbance and response by small mammals and birds in chaparral near urban development. Urban Ecosyst 2:279-297 doi:10.1023/A:1009588723665

Scheun J, Bennett N, Ganswindt A, Nowack J (2014) Spicing up the menu: evidence of fruit feeding in Galago moholi. Primates 55:359-363 doi:10.1007/s10329-014-0420-8

Schülke O, Kappeler PM (2003) So near and yet so far: territorial pairs but low cohesion between pair partners in a nocturnal lemur, Phaner furcifer. Anim Behav 65:331-343 doi:http://dx.doi.org/10.1006/anbe.2003.2018

Shutt K et al. (2014) Effects of habituation, research and ecotourism on faecal glucocorticoid metabolites in wild western lowland gorillas: implications for conservation management. Biol Conserv 172:72-79 doi:http://dx.doi.org/10.1016/j.biocon.2014.02. 014 
Spellerberg IAN (1998) Ecological effects of roads and traffic: a literature review. Glob Ecol Biogeogr 7:317-333 doi:10.1046/j.1466-822x.1998.00308.x

Tecot SR (2013) Variable energetic strategies in disturbed and undisturbed rain forests: Eulemur rubriventer fecal cortisol levels in south-eastern Madagascar. In: Masters J, Gamba M, Génin F (eds) Leaping ahead. Developments in primatology: progress and prospects. Springer New York, pp 185-195. doi:10.1007/978-1-4614-4511-1_21

Touma C, Palme R (2005) Measuring fecal glucocorticoid metabolites in mammals and birds: the importance of validation. Ann N Y Acad Sci 1046:54-74 doi:10.1196/annals.1343.006

Touma C, Sachser N, Möstl E, Palme R (2003) Effects of sex and time of day on metabolism and excretion of corticosterone in urine and feces of mice. Gen Comp Endocrinol 130:267-278 doi:http://dx.doi.org/10.1016/S0016-6480(02)00620-2

Tuomainen U, Candolin U (2011) Behavioural responses to human-induced environmental change. Biol Rev Camb Philos Soc 86:640-657 doi:10.1111/j.1469185X.2010.00164.x

van Doorn AC, O'Riain MJ, Swedell L (2010) The effects of extreme seasonality of climate and day length on the activity budget and diet of semi-commensal chacma baboons (Papio ursinus) in the Cape Peninsula of South Africa. Am J Primatol 72:104-112 doi:10.1002/ajp.20759

Voragen AGJ (1998) Technological aspects of functional food-related carbohydrates. Trends Food Sci Technol 9:328-335 doi:http://dx.doi.org/10.1016/S0924-2244(98)00059-4

Yeo J-H, Neo H (2010) Monkey business: human-animal conflicts in urban Singapore. Social \& Cultural Geography 11:681-699 doi:10.1080/14649365.2010.508565 